\title{
New paradigm of the Russian labor market in the context of the formation of an inclusive economy and a new gender order
}

\author{
Galina Georgievna Sillaste ${ }^{1}$ \\ Financial University under the Government of the Russian Federation, Department of Sociology, \\ Faculty of Social Sciences and Mass Communications, Moscow, Russia
}

\begin{abstract}
The author considers the profound changes that have occurred in the Russian labor market during the transition from a transitive economy to an inclusive one and the expanding influence of the emerging gender order, the theoretical concept of which is the theory of gender neutrality. A new paradigm for the development of the Russian labor market is proposed, which meets the radically changed economic and social conditions for the development of socio-gender labor resources in the conditions of digitalization. According to the author, a new multi-vector structure has formed in the Russian economic space, consisting of four closely interrelated markets: labor, employment, professions, and educational services. The labor market and the employment market have become the epicenter of the development of social inclusion and an inclusive economy, which have presented qualitatively different requirements for socio-gender labor resources. The complex interrelations between the four segments of the new structuration are analyzed as deep structural changes and tectonic shifts in the formation of socio-gender labor resources, the implementation of their social functions, and the reformatting of social mechanisms for managing ongoing processes. The inertial view of the labor market as a single social space does not correspond to the realities of its modern development. The article reveals the essence of the new social structuration in the context of the theory of Giddens, its architectonics, logistics of development, dialectics, and social multidimensionality. The trends in the development of a new social structuration are evaluated through the standpoint of the formation of a new gender order and the theory of gender neutrality.
\end{abstract}

Keywords: socio-gender and labor resources, world gender order, inclusive economy, four-segment structure, social space, labor market, employment market, profession market, educational services market, gender neutrality

\section{Introduction}

\footnotetext{
${ }^{1}$ Corresponding author: galinasillaste@yandex.ru
} 
The development of the economy and types of labor activity is closely interrelated with the changes in the field of labor employment, the distribution of labor resources, including socio-gender resources. This process is currently determined by two factors: a developing inclusive economy and a new gender order developing in the world. The goal of an inclusive economy is to ensure equal access for people to economic independence and unhindered interaction between social groups. The driving force of an inclusive economy is the development of a socially-oriented approach in two directions: the first is to ensure economic growth by involving the poor population in economic activity; the second is to create resources, primarily human, labor, socio-gender, for the functioning of an inclusive economy.

There have been profound structural changes and movements of labor resources over the past 30 years that have changed the traditional perception of the labor market as a single social whole for Russians. Earlier, in the sphere of labor, the state was the determining regulator, the monopolistic institution responsible for the formation of the labor sphere, and the institutions of education, labor, production, distribution and consumption, law and management were a single well-coordinated mechanism. In a transitive, and even more so in an inclusive economy, the social interests of the population and those who are preparing to enter the labor market do not always coincide with the interests of the institutions of the state, economy, and production. Moreover, education as a social institution has greatly changed its social functions, becoming one of the markets for intellectual services. This market, which is directly connected with the digitalization of the economy, is the generator and driving force of a new four-segment structure. At the same time, structuration is considered by the author (in accordance with the theory of Giddens) as a process of organization and reproduction in the system of social relations, accompanying the social interaction of actors (subjects). A new system of rules and the availability of resources generate a new social system of labor relations and the distribution of labor resources.

The architectonics of the new social structuration, within which four interconnected markets function, nevertheless preserve the dialectics and consistency of the social process, production and reproduction of basic labor resources. In fact, the institution of education remains the recreator of new labor socio-gender resources. This institution has changed its social functions, opened its social and educational space to market mechanisms of profit and commercialization, and become a leading producer of the educational services market. Along with it, the budgetary basis for the admission of students to universities is preserved as proof of the implementation of the constitutional right of an individual to affordable education.

The theory of gender neutrality, which is the leading conceptual basis of the new gender order, assumes the removal of restrictive barriers from the sign of gender not only for obtaining any kind of education but also for any profession at the request of men and women. Thus, the new gender order contributes to the expansion of gender equality in the new structuring of the market space.

To analyze the complex and contradictory, hidden from the external view, social processes accompanying the development of labor markets, employment, professions, and educational services, the author uses a multi-paradigm approach. This approach synthesizes a set of theories, concepts, and paradigms in the field of economics and labor sociology: Changli [1], Slezinger [2] (in the field of social economics), Oleynik [3] - institutional economics, and also the paradigms of "new economic sociology" by Svedberg and Granovetter - a concept of the author's approach to the analysis of new structuration develops. A number of particular sociological theories complement the indicated methodological principles of analysis: the sociology of labor (Yadov, Fetisov, Toshchenko, 
Aitov), the sociology of markets (Polanyi, Braudel - theories of the public and private market), Jevans (theory of political economy), risk theory (Beck - Risk Society. Towards a New Modernity), Prigozhin, Kravchenko, Krasikov [4], the theory of gender sociology and the new world gender order (Sillaste [5]), the theory of structuration (Giddens) and the theory of social change (Shtompka). In the analysis of the gender specifics of the workforce, the emphasis is on the theory of gender economics (Jacobsen, Kalabikhina), theories of gender discrimination and gender segregation.

\section{$2 \quad$ Materials and methods}

Various methods of analytical search were used for studying the functioning of the new structuration: the results of a public opinion poll, regional sociological studies, analysis of gender statistics at the country level, methods of standardized interviews and included observation, and others. These methods were used as a tool for studying socio-gender labor resources, labor activity, and labor force of a developing inclusive economy.

The study proceeds from the simplest postulate of the structuration theory, which states that resources arise only as a result of human activity and are changed and maintained only by people. Thus, a specific labor resource type arises - socio-gender resources. To analyze their development and influence on the social tectonics of the labor market, one should turn to the gender structure of society and the new norms of the gender order. The universal norm of the new gender order is the legal and social norm for overcoming segregation and social discrimination, which can ensure the observance of gender equality in society.

The achievement of gender equality is closely related to the gender structure of the population both in society as a whole and in the economy specifically. If the global gender landscape of the world's population structure is dominated by men $-51 \%$, then in Russia there is a steady predominance of women (by 11 million) over the number of men. Russia is traditionally the most feminized country in the world, which affects the system of gender interaction: from the family to the markets of labor, employment, professions, and educational services. The feminization of society has a strong influence on the formation of modern social and gender policy of the state and is fully reflected in the distribution of socio-gender labor resources in all areas of employment.

Gender labor resources, according to the author's definition, are a type of social resources of male and female gender communities, which in the course of labor activity are transformed into an effective mechanism for the development of the national economy, including a mechanism for the development of a new structure of the markets of labor, employment, professions, and educational services. As a type of resources, gender resources are considered as a means, value, reserves of opportunities, and a source of income. They belong to the group of renewable, depletable, and unchangeable labor resources. These resources are measurable, organized, and managed in the process of achieving social and economic goals.

Gender resources are made up of able-bodied men and women and can be attributed to the most universal resources that can act as a kind of "universal equivalent" and a measure of social development along with information, time, and money. At the same time, gender resources are fundamentally different from other types of economic resources, since they are a factor of social production and development, in which human capital is accumulated. Gender labor resources are directly related to the development of the gender economy, the subject of which is the gender factor of economic development and its impact on the economy. Based on the social characteristics of gender resources, intellectual capital is developing in the economy as the basis of its new industries, and it is based on the intensive 
use of knowledge (knowledge-based industries). Gender labor resources can be considered unique and universal resources, without which the creation of public goods is impossible, and the effective use of these resources can be considered an axiom of reasonable state management.

\section{$3 \quad$ Results}

Further, four market types in the new social structuration are considered. For the first, the labor market is not adequate to the employment market. These are markets with different social objects, differing in the degree of their mobility, labor activity, and types of labor activity. The employment market has the highest mobility today. The social object of the employment market is the able-bodied population and also persons older and younger than the working age, who are able to work. Among them, $76.1 \%$ are women, $82 \%$ are men [1]. There may be migrants among the employed, unemployed, job seekers and those who have found a job, men and women working under an employment contract, including those who perform work for remuneration on full or part-time terms, and those who have other paid work (service), including seasonal, temporary work, with the exception of public works. A certain part of the employed are teenagers who can earn money (from the age of 14), the economically active population, retired, but ready to work or earn extra money, receiving a certain income. According to the form of employment, it can be temporary, discrete, long-term, short-term, full or partial, primary or secondary, legal or shadow.

The labor market is a sphere of supply and demand for labor that can perform various types of labor activities. The volume of the labor market is the entire working-age population (82.2 million people), $49 \%$ of whom are women. In 2017, the labor force of the Russian labor market was 76.1 million people, whose gender structure is asymmetric in favor of men (38.2 million people against 35 million women). At the same time, if in 1991, $91 \%$ of enterprises in the Russian economy were state-owned, then in $2019,4 \%$ of employees worked at state-owned enterprises, and $87 \%$ worked in privately-owned companies. Also, women prefer to work in the public sector of the economy, considering it socially more protected, stable, and gender-equal. The educational potential of Russian women in the labor market is higher than that of men. Important changes in the characteristics of the labor market were made by the pension reform of 2019, which changed the gender "rocker" of retirement, raising the age limit of male pensioners to 65 , and women to 60 years.

The market of professions is a sphere of supply and demand for various types of specialties and professions that are in demand by the economy at different stages of its development. The volume of the market of professions is reproduced by the institution of education, supported by the change in the request of employers and the dramatically expanded alternatives to choosing employment in the digital economy. The market of professions in terms of its volume and variety of professional activities directly depends on the historical conditions and the level of technical development of society. If in the 17th century, there were only 200 professions in Russia, and they were mostly male, then the international standard of classifications of professions in 2019 recorded 9,993 professions, of which 7,000 are sold in the Russian market of professions. In megacities, the market for professions is about 5,000, and in medium-sized cities, it reaches 3,000 specialties. The theory of gender neutrality in the context of the formation of a new gender order has a positive impact on the market of professions, since in recent years it has contributed to the removal of discriminatory barriers for women from 1,356 professions in which Russian 
women can now work. There are only 100 specialties left in the barrier zone that have gender restrictions on their accessibility for women.

Sociologically, professions can be classified into 6 groups of demand: dying, obsolete intellectual professions, obsolete working professions, popular professions, required professions, and mass ones. The modern market of professions is characterized by their accelerated renewal.

As for the development of the educational services market and the institution of education as a generator of the professions market, due to the "Education without Borders" strategy, the educational services market has expanded the traditional age-limiting framework of students of socio-gender communities to age infinity. The introduction of "Silver Education" programs, education beyond the age significantly prolonged the creative and intellectual capabilities of men and women. The issue of gender equality in the educational services market is also being formatted in a new way, based on their new norms of the new gender order. However, this is the subject of further analysis.

\section{Discussion}

The problem of the development of a new social structuration instead of the once unified labor space can be considered as a subject of scientific discussion for economists and sociologists. However, it is obvious that the transition to an inclusive economy, the inclusion of new groups in the labor process (and these are not only groups of disabled people and people with disabilities) make corrections to the traditional ideas about a certain single "labor market". This process results in tectonic shifts within the old model of the labor market, multidimensional expansion of employment opportunities, and employment of representatives of male and female socio-gender communities under the influence of digital technologies and new norms of the gender order.

\section{Conclusion}

1. In Russia, a qualitatively new social structure has been formed and it is developing in the conditions of an inclusive economy and the formation of a new global gender order, consisting of 4 markets: labor, employment, professions, and educational services. Each of them is distinguished by existing social facilities, their scale, prospects, and social mechanisms of employment and internal development.

2. The study of the new social structuration is carried out from the point of view that improving the quality of socio-gender resources of economic development will make it possible to better predict, plan, and redistribute their flows along the trajectories of four dependent markets. This will make it possible to integrate the related demands of economic and social policy, to increase the effectiveness of the social mechanism for regulating the reproduction of socio-gender labor resources of a new quality that meets the implementation of the sustainable development strategy-2030.

\section{References}

1. I.I. Changli, Rabota [Work] (TSP, Moscow, 2002)

2. G.E. Slezinger, Sotsialnaya ekonomika [Social Economy] (Publishing house "Business and Service", Moscow, 2001) 
3. A.N. Oleynik, Institutsionalnaya ekonomika [Institutional Economics] (INFRA-M, Moscow, 2000)

4. S.A. Kravchenko, S.A. Krasikov, Sotsiologiya riska: Poliparadigmalnyi podkhod [Sociology of Risk: A Polyparadigm Approach] (Ankil, Moscow, 2004)

5. G.G. Sillaste, Woman Rus Soc, 2, 3-16 (2019). https://doi.org/10.21064/WinRS.2019.2.1 